\title{
A Conceptual Framework for Smart Homecare
}

\author{
Sujata Basnet ${ }^{1}$, Ashab Abid ${ }^{2}$, Moshiur Bhuiyan²* ${ }^{2}$ P. W. C. Prasad ${ }^{1}$ \\ ${ }^{1}$ School of Computing and Mathematics, Charles Sturt University, Sydney, NSW 2010, Australia. \\ ${ }^{2}$ Service Consulting, Enterprise Cloud Systems Pty Limited, Sydney, NSW 2560, Australia. \\ *Corresponding author. Email: moshiurb@ecloudsys.com \\ Manuscript submitted September 11, 2017; accepted November 24, 2017. \\ doi: 10.17706/jcp.13.7.733-749
}

\begin{abstract}
This research aims to develop a "Conceptual Framework for Smart Homecare" that emphasizes to optimize the homecare processes in terms of quality and cost efficiency. It proposes best-of-breed process using the organisational and technological ecosystem. The existing eco-systems of the health management devices available in the market have limitations especially the architecture lacks the organizational view of the overall processes. The conceptual model is proposed through incorporating an $i^{*}$ model into the early phase of requirements engineering. It has been argued that such notations help answer questions such as what goals exist; how key actors depend on each other and what alternatives must be considered. The frameworks also suggest required process with associated actors, along with its dependencies and goals. In this paper, we took the opportunity to begin research on the discovery, documentation and modelling of existing and future processes in Smart Homecare that can potentially guide organisations wishing to offer these services.
\end{abstract}

Key words: Smart homecare, organizational models, i*, conceptual framework, strategic dependency, strategic rationale.

\section{Introduction}

\subsection{Background}

Health has always played a crucial role in everyone's life. Several types of health monitoring devices have been developed due to the advent of new ICT (Information and Communication technology) are adopted to cater for patients with the motive of helping the people to maintain their [1]. Currently, chronic diseases such as heart related issues, diabetes, asthma accounts for almost $80 \%$ of the total diseases and it is expected to rise over the period [2]. Our proposed conceptual framework for Smart Homecare aims at benefitting the primary health care management. The existing health care management system needs to go through a very complicated and multiple processes. In addition to this, it seems there has been no best practice of the process in Health sector that we could optimize the process to make in terms of efficiency and quality.

\subsection{Significance of this Research}

Our proposed work aims to address the gap of social and intentional characteristics of actors in organizational setting including the goals of participants and their inter-dependencies in designing the conceptual framework. This high-level conceptual framework will allow the citizens and the governments to manage their primary health making significantly flexible, efficient and feasible.

Investigation into Smart Homecare business processes requires the following: 
- Discovery of the actors and their strategic dependencies used in organisations offering Smart Homecare services for the remote management of a patient's health.

Outcome: Identification of the underlying organisational template for Smart Homecare and the processes and/or activities required to enable it.

-A formal articulation of Smart Homecare business processes that identify all dependent or influencing process factors such as organisational business environments, structure, people, etc.

Outcome: Model in $i^{*}$ organisational modelling notation the Smart Homecare conceptual model using organisational templates.

\subsection{Purpose and Aims}

This research aims at developing a conceptual framework for Smart Homecare that emphasis on optimizing the processes in terms of quality and cost efficiency that helps in converting them into a single best-of-breed process. Developed countries such as Australia where the population has been increasing with significantly high number of senior citizens and people with chronic diseases. These two groups seek more than half of primary health care assistance. There has been a steady growth in Medicare expenditure and the need for efficiency in health care processes is vital. Our proposed framework aims to address this efficiency question and seeks to discover health processes and modelling in Smart Homecare setting.

The main aims that are performed to address the research questions are listed below:

- To discover and design conceptual framework for Smart Homecare using organizational model.

- To develop business process templates for Smart Homecare.

- To develop models of Smart Homecare business process.

\section{Literature Review}

Current literature addresses health management options using technology and systems significantly with many open questions left to be answered. Different enterprises level devices, system have been developed with the motive of providing a solution to some extent that would help people to monitor patients' health monitoring such as blood pressure, sugar, asthma etc. Smart home devices basically focus on clinical assessment and provide with different status of health.

\subsection{Comparison among Existing Frameworks and Architecture}

Till now the available device that has been on market lately uses different architecture and frameworks. The available frameworks and architectures talk about how each component of the information system works with the identification of processes required. The available information system including remote based devices and information system, as per their functionality and the purpose different architecture has been implemented [3]. Based on their functionality, from the literature review, further analysis of the architecture are frameworks are carried out.

As per [4] in a health scenario, automating the health services with an alert response to various health staffs to health and health status of the patient makes people aware of their situation as well as to cope up with any kind of emergency in future. The developed frameworks can be incorporated with the existing clinical measurements available, it provides the new CAAB measurements that can be implemented by the clinical personals as it is a smart home based predictions that help in the decision-making process in the health sector [4].

The CAAB framework proposed for behavior assessment of the patient it uses CAAB framework. With the existing clinical measurements available to check the status of the patient, it provides the new CAAB measurements that can be implemented by the clinical personals as it is a smart home based predictions that help in the decision-making process in the health sector.However, the framework is limited as it does 
not explain the core processes that are involved in it like the what kind of process happen and how all the communication are carried out and what kind of information are exchanged.

Whereas, the (FLES) is a capable multi-device Framework to increase self-awareness for health and disease prevention that can be implemented in a wireless device that updates patient with health status.The growing concerns regarding the health of the people are crucial however with the invention of different health management applications and systems do help in a respective way. One of the frameworks that could be implemented in a wireless device that helps in providing a full control of personal health [5]. It is Cost effective, Easy to implement, Platform compatible, Convenient to use [5]-[7]. FLES Framework is one of the effective and compatible platforms that can be integrated into any devices as requires. As most of the people uses mobile devices that would be more convenient and effective if it could be handier with its implementation and coming up with additional features. Furthermore, it only focuses on the calculation of health status but doesn't specify any kind of communication with the other actor that plays an important role in the overall health management.The following diagram has been generated.

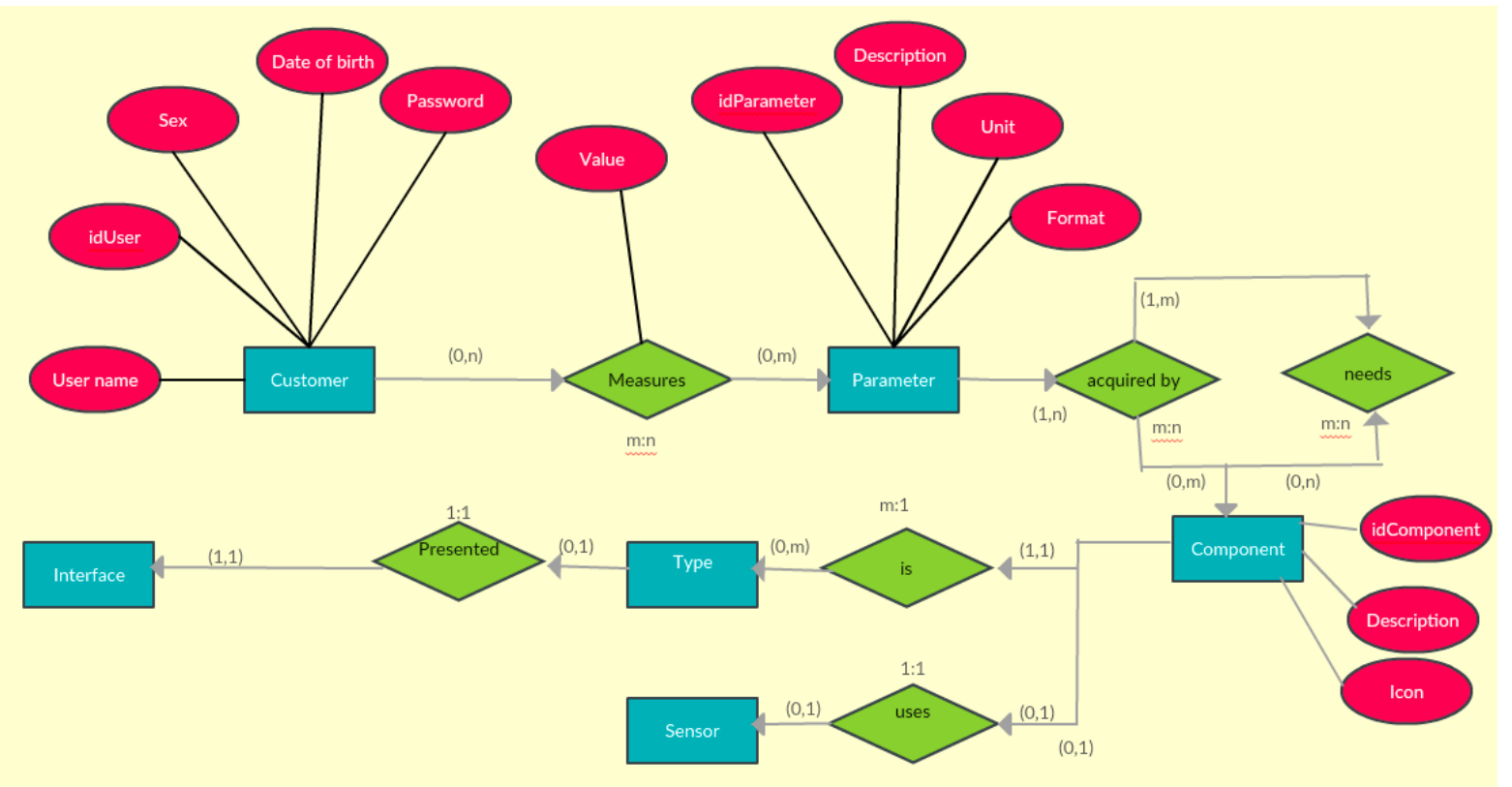

Fig. 1. ER model of supporting database.

The model proposed by [8] known as Signed digraph and cybernetic feedback formalisms are sued for the conceptual systematic approach that helps in providing best ICT strategies. The model-based Conceptual model has been practically implemented in three different states so far and has proved to be successful [8]. It is important when it comes to reengineering the medical processes and maximizing the value added by telemedicine and Telecare services. The goal of this solution is to provide with the best ICT Strategies that can be adopted to make it more effective and efficient that helps in maximizing the benefits of tele care services. Since it is very hard to determine which strategies to adopt that suit best. It solely helps in making a strategic decision in terms of its efficiency and effectiveness with different parameters. Decision support system architecture, the system ultimately helps in the overall proper health management notifying with an alert if anything serious conditions occurs.

This type of model and framework would highly help in the decision-making process that would ultimately be beneficial to everyone's health. The framework facilitates the ability to incorporate the patient's condition and medication details in the interface and provide recommendation that can be 
implemented locally by health centers and the Government Authorities to localize the complex process in an effective way.

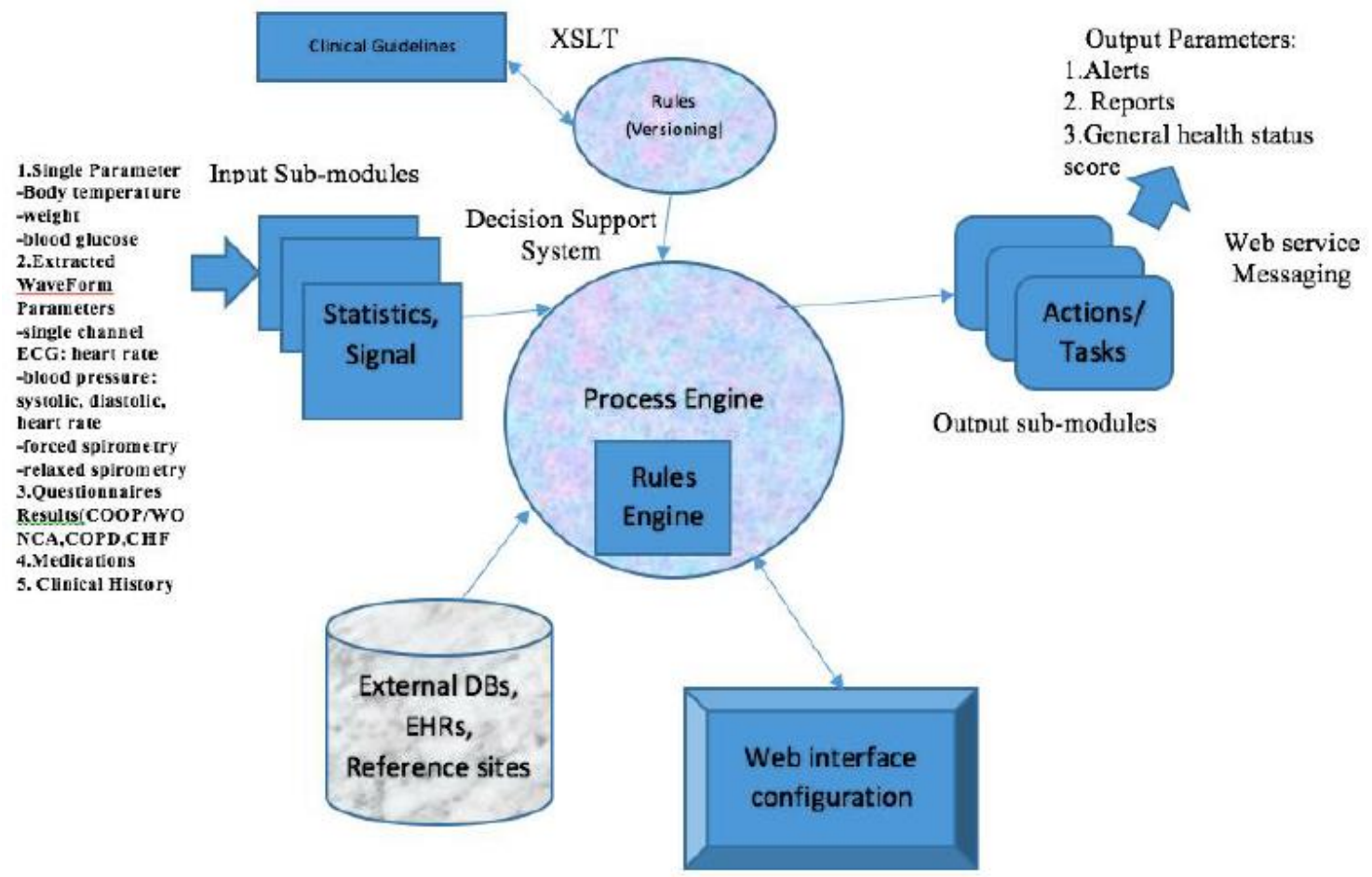

Fig. 2. Decision support system for home telecare.

The accomplishment of the developed services for managing the health is tremendously growing. The developed systems till now from a remote based device to cloud-based system, most of it are based on the basic component of decision support system, the cloud-based database that would work on the how the flow of information is managed and how the analysis is carried out to provide health status of people with the given information. Recent works shows, different devices has been used for behavioural assessment that works and process and predict their health status based on the activities they perform [9]. To perform those processes, Decision support system plays a vital role as most of the literature review were about how decision support system helps in identifying and analysing the data. Different component of the system that are important aspects of the Smart Homecare System were identified with most of the similar commonalities from decision support system, data mining algorithm to analyse the statistical data, when there comes a data, a database of limited to component of the system as in general, openEHR that facilitates fetching and storing multi-institutional data. All the identified architecture deal with the big data and some of them are platform independent.

The model-based conceptual model proposed by Xu and Cai [7] provide scalable cloud computing based architecture to design health monitoring system for health care agencies. Cloud storage, service composition, and flexibility within this architecture give extra addition to this work. Since this project is focusing on the Cloud service integration in a system that would provide with a view how data can be maintained in iCloud and databases as well as a decision-making process. It provides the knowledge regarding the health monitoring system that integrates domain knowledge with description of relationships between physiological index values and diseases in graph to assess the health conditions of the health monitoring service subscribers. A process of $m$ health monitoring and A PI-D Graph has been generated to show how the inputs are calculated as per the model proposed by [8]. 


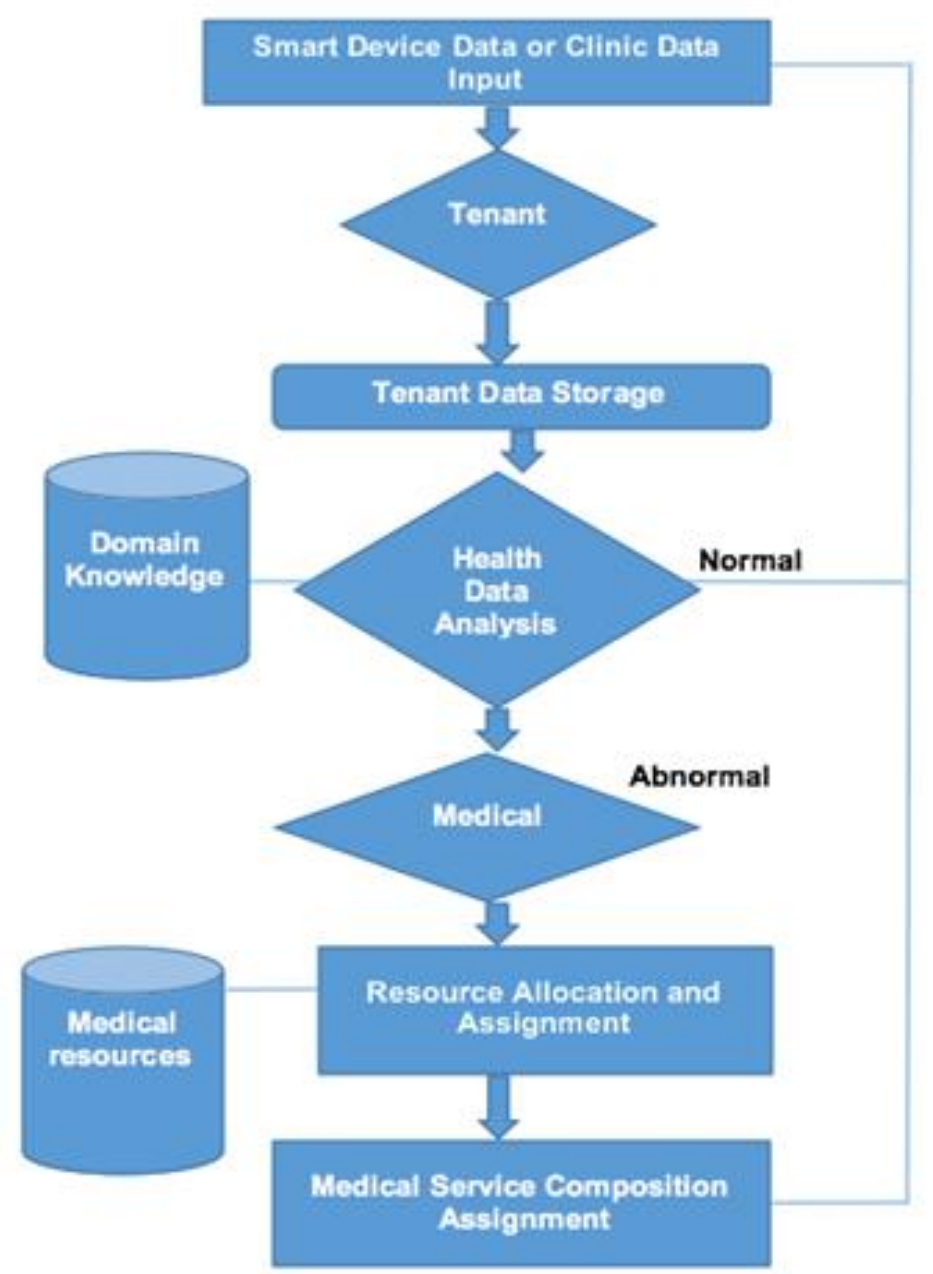

Fig. 3. Process of $m$ health monitoring angicardiopathy.

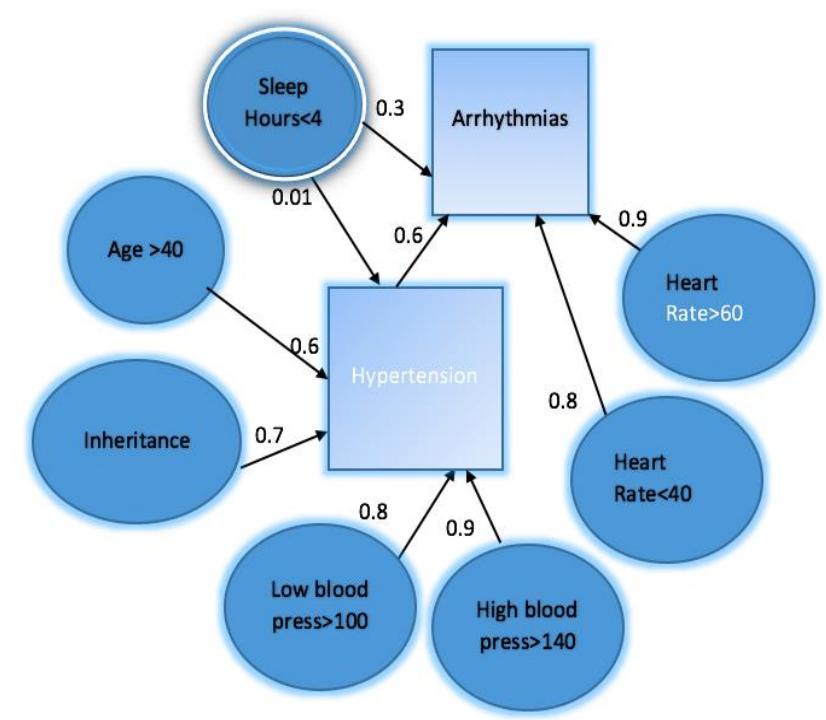

Fig. 4. A PI-D graph.

The accomplishment of the developed services for managing the health is tremendously growing. The developed systems till now from a remote based device to cloud-based system, most of it are based on the 
basic component of decision support system, the cloud-based database that would work on the how the flow of information are managed and how the analysis are carried out to provide health status of people with the given information. Recent works shows, different devices has been used for behavioural assessment that works and process and predict their health status based on the activities they perform [9]. To perform those processes, Decision support system plays a vital role as most of the literature review were about how decision support system helps in identifying and analysing the data. Different component of the system that are important aspects of the Smart Homecare System were identified with most of the similar commonalities from decision support system, data mining algorithm to analyse the statistical data, when there comes a data, a database of limited to component of the system as in general, openEHR that facilitates fetching and storing multi-institutional data. All the identified architecture deal with the big data and some of them are platform independent.

\section{2. $\quad i^{*}$ Modelling Framework}

The central concept in $i^{*}$ is that of the intentional actor (agent). Intentional properties of an agent such as goals, beliefs, abilities and commitments are used in modelling requirements [18]. The $i^{*}$ framework consists of two main modelling components: The Strategic Dependency (SD) Model and the Strategic Rationale (SR) Model.

\subsubsection{Strategic dependency model}

The SD and SR models are graphical representations that describe the world in a manner closer to the users' perceptions [10]. The SD model consists of a set of nodes and links. Each node represents an "actor", and each link between the two actors indicates that one actor depends on the other for something in order that the former may attain some goal. The depending actor is known as depender, while the actor depended upon is known as the dependee. The object around which the dependency relationship centres is called the dependum. The SD model represents the goal, task, resource, and soft goal dependencies between actors/agents.

In a goal dependency, the depender depends on the dependee to bring about a certain state in the world. The dependee is given the freedom to choose how to do it. In a task dependency, the depender depends on the dependee to carry out an activity. Task and goal dependency may often appear interchangeable. One way to understand the distinction is to view goals as more coarse-grained, abstract entities and tasks as more fine-grained, specific entities (while recognizing that goals can always be reformulated as tasks and

vice versa). Another dimension to this distinction is the relative autonomy of the dependee in deciding how a goal is achieved, while in a task the depender and dependee must coordinate in a far more tightly coupled fashion. In a resource dependency, one actor (the depender) depends on the other (the dependee) for the availability of a resource. In a softgoal dependency, a depender depends on the dependee to perform certain goal or task that would enhance the performance. The notion of a softgoal derives from the Non-Functional Requirements (NFR) framework and is commonly used to represent optimization objectives, preferences or specifications of desirable (but not necessarily essential) states of affairs.

\subsubsection{Strategic rationale model}

An SR (Strategic Rationale) model represents the internal intentional characteristics of each actor/agent via task decomposition links and means-end links. The task decomposition links provide details on the tasks and the (hierarchically decomposed) sub-tasks to be performed by each actor/agent while the means-end links relate goals to the Agent-Oriented Methodologies, resources or tasks required to achieve them. The SR model also provides constructs to model alternate ways to accomplish goals by asking why, how and how else questions. A Strategic Rationale model for Patient Treatment Process has been illustrated below in Fig. 5: 


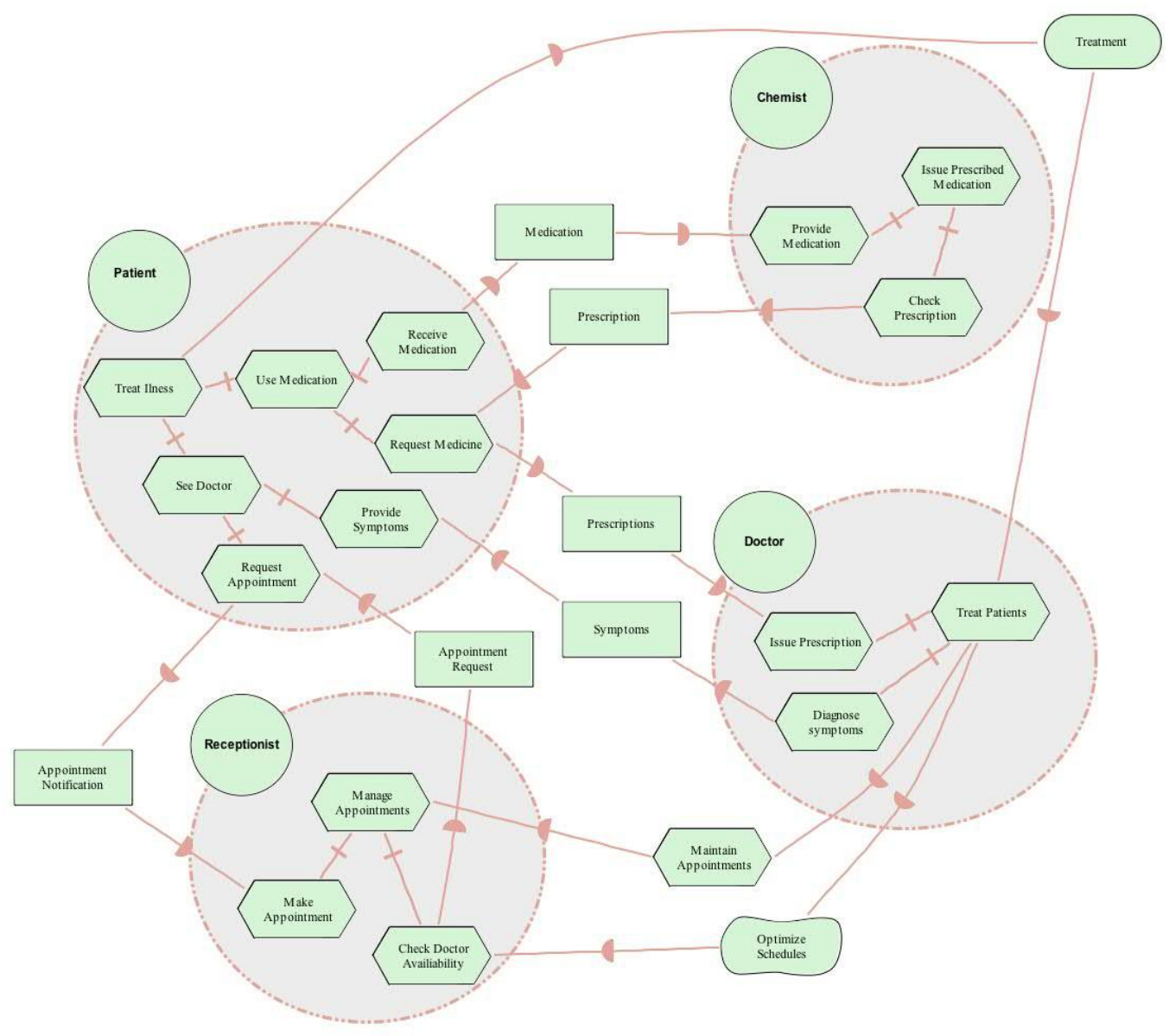

Fig. 5. Strategic rationale model of patient treatment process.

\subsection{Traditional Chronic Disease Treatment Process and Smart Homecare}

The Australian Institute of Health and Welfare (AIHW) reports that $77 \%$ of the population have at least one chronic medical condition, and that $80 \%$ of the burden of disease and injury in Australia is attributable to chronic diseases. The major chronic disease is accountable for high expenditure. Chronic disease is a diverse array of medical conditions. Chronic diseases such as diabetes, heart stroke, asthma, cancer are widely distributed in the Australian population with high risk because 54\% of adults being either overweight, $50 \%$ not getting sufficient physical activity and $21 \%$ smoking tobacco [11]. The Australian Institute of Health and Welfare and the National Chronic Disease Strategy, have specifically defined chronic diseases with the following features:

- Complexity and multi-factorial causes

- Gradual or sudden symptoms observed with certain stages or periods

- Long term in nature causing worsening of health.

- Gets more dominant with the older age.

- Compromise the quality of life through different physical limitation and disability.

- Slowly but eventually leads to the premature mortality.

\section{Concept of Chronic disease management}

The given chronic disease care management is known as Kaiser Triangle, is divided into three level. It illustrates the individual patients require different level of care and treatment starting from personal health management approaches to intense health management. A brief description of each level is given below 
[12]:

\section{Level 3: High complexity case management}

It is assigned to chronic disease patients with complex needs who has to use hospitals frequently.

\section{Level 2: High risk disease or Care Management}

It is assigned to provide an enhance self-care skills using clinical management protocols.

\section{Level 1: Self-care support management}

It is assigned to chronic disease patients with or without complex needs who requires primary health self-care management.

According to the Ministry of Health [13], a model for care has been identified in the given diagram Fig. 6 and 7.

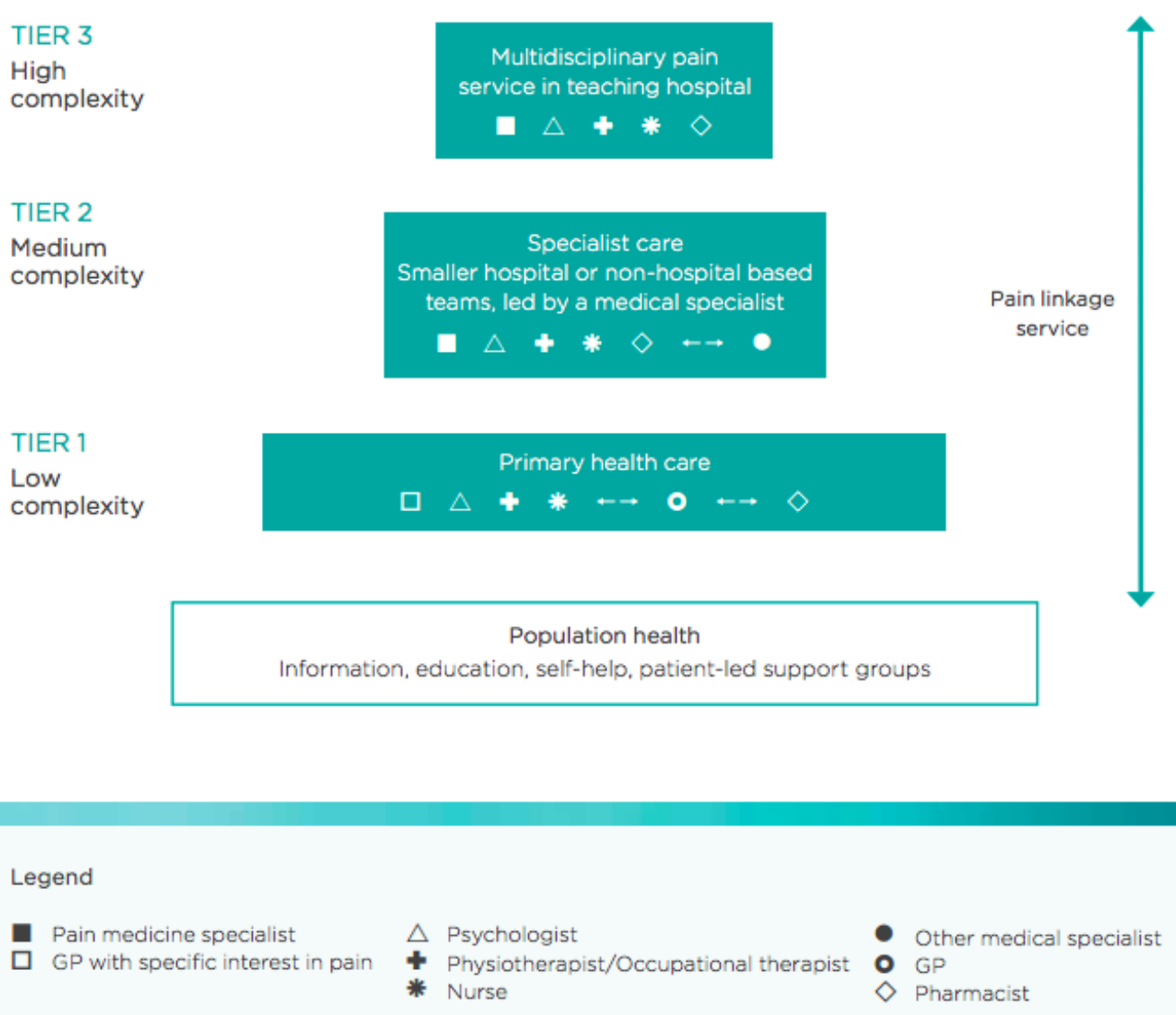

Fig. 6. Proposed model of care management.

The increasing aging population and late retirement age are one of the major reasons because of which people who are more likely to suffer from chronic diseases as primary health management is still overlooked. As a result, it extended different factors such as health cost services and living standard of the people. Due to the ongoing problem to maintain a health of the patient to be more economically feasible and efficient, Smart Homecare has been introduced. This plays an important role in level 1 of Chronic Disease Care Management as a part of primary health management [14]. The proposed Smart Homecare framework that would be incorporated in a remote device that would help a patient to maintain their primary health status by providing a remote access to the patient via Smart Homecare Device. In addition to this, a patient can stay at home in a safe environment without any wait and effort for the normal health status check-up such as blood pressure, sugar and a range of other vital signs. At the same time, the amount 
of money and effort a Government putting in the health sector can be minimized and can be more effective without cutting off any facilities to the patients. Smart Homecare will be able to communicate with all the actors that are important to maintain an overall health management system.

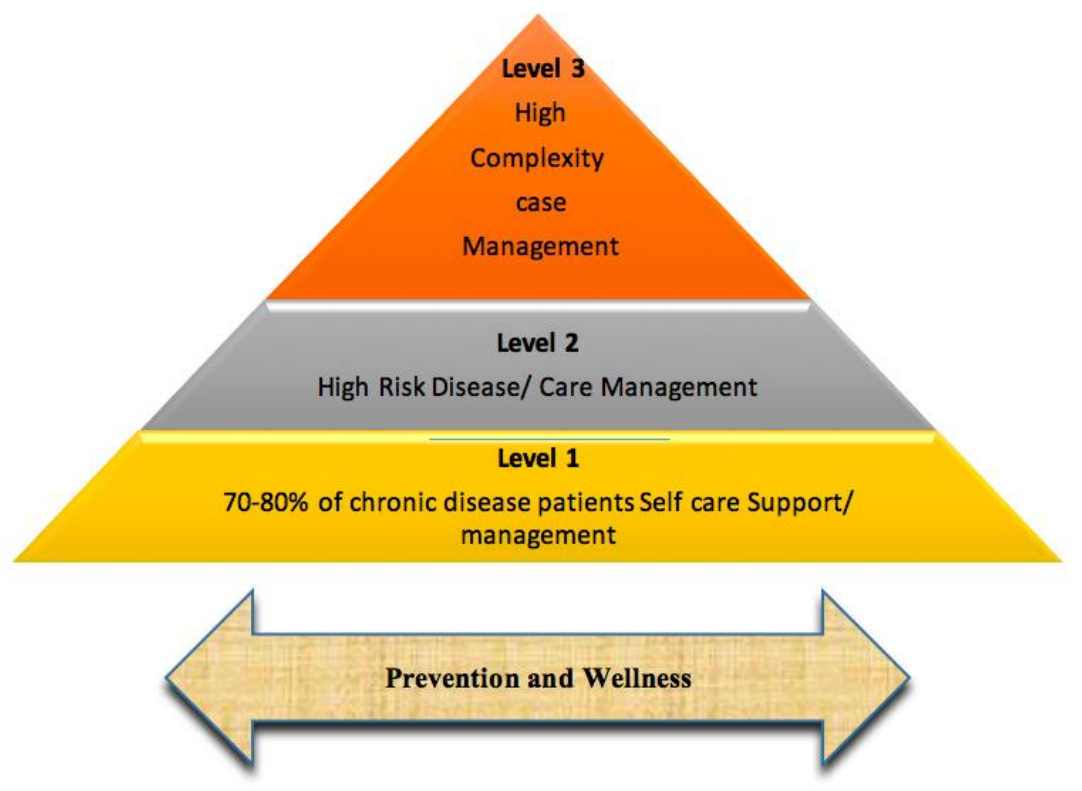

Fig. 7. Three level view of chronic disease care management.

\section{Proposed Conceptual Model for Smart Homecare}

\subsection{Identification of Actors}

From the study of literature Review, different available health system, and the frameworks has identified some of the processes and actors that can fit into the conceptual framework for Smart Homecare. Correlated actors are discovered and further elaborated along the associated roles played by each actor while performing the process [15]. The list of actors is briefly given below:

- Patients

- Smart Homecare Device

- General Practitioner

- Decision Support System

- Ambulance

- Patient carer

- Central care team

- EPRS

- Receptionist

- Medicare

- Community nurse

The roles of different actors are defined carefully as they have the deep impact on the Conceptual diagram of the Smart Homecare. The rules stipulate the scope of the each identified actors in the Smart Homecare domain. Likewise, the importance should also be given on Patient's information that is accessed by different actors. On the basis accessibility, roles are identified for each actor. Roles of above identified actors are described briefly: 


\section{Patient}

The patient is recognized as the main actor for whom the services are targeted for. The patient is the actor who suffers from for the main actor who suffers from different diseases and would be using a Smart Homecare. They are facilitated for treatment services. The provided services are and facilitate with the services of treatment. These provided services are delivered by the above identified external Actors such as GP, Hospital, Ambulance, Ambulance, Community nurse, Patient carer and much more.

\section{Smart Homecare Device}

This is an electronic device known as Smart Homecare that is responsible for taking input from patients like measurement and health status and update them in electronic patient records that are linked to other associated actors.

\section{General Practitioner}

General Practitioner (GP)'s plays a crucial role to analyse the patient's condition and advise them about the current status of health and provide prescriptions and provide medications as per the conditions. They also instruct patients about lifestyles and in the case of some chronic disease and if necessary they refer to the specialist. They are the also considered to be playing a very big role in health management as for any kind of diagnostic test, for making an appointment they provide availability to both Patients and Receptionist.

\section{Decision Support System}

Decision Support System is a backbone of the framework as all he measurements are performed by the Decision Support System to determine the health status of the people [16], [17]. All the necessary measurements are gathered from the Smart Homecare Device and medication and medication history of the patients are extracted from the EPRS System.

\section{Ambulance}

This actor's role is to communicate to the other existing actors such as receiving the emergency messages from the patients, GP, Patient carer, and providing a quick possible service and the immediate response at the time when the treatment is necessary.

\section{Community Nurse}

Community nurse as an integral part, help the patient to control their health status to make sure the patients are in stable condition. Community nurse co-ordinate with the patient suffering from different kinds of diseases and GP, Hospitals, Carers, other clinics, to give patient level 2 and level 3 services if required.

\section{Electronic Patient Record System (EPRS)}

Electronic Patent Records System is a system that is built to store the measurements provided by the patients and the medication they are on. It keeps a record of the history of patient health.

\section{Central Care Team}

Analysing the current situation and needs, Central care Team plans on the patient state, by making an immediate decision like sending an ambulance or informing the GP, patient or community nurse.

\section{Receptionist}

GP's Receptionist acts as a mediatory role for making an appointment with mainly Patient but also Patient Carer. Receptionist gathers availabilities from GP and Patients, and make an appointment and send the reminder to patients about appointments. The visit logs of every patient, payment bills, and processing payment are handled by the Receptionist. All the identified process performed by the Receptionist, are related to the Smart Homecare, however, it may vary as depending on the different structure of the treatment process such as Surgery.

\section{Patient Carer}


Patient Carer plays very important role in Smart Homecare process. Patient carer actor can be any person who is responsible for taking personal care of Patient actor. The patient carer can be any from the community or from the family members. The ultimate motive of patient-carer is to help the patient with the regular measurements of current patients' condition, instructing how to take medicine and reminding to take the medicine on time. In the case of inconvenience, they help patients while visiting GP. Patient carers are a voluntary role however; it plays a significant role as it will perform the similar roles as the patient actor has an ability to replace the similar kinds of process. When it comes to the accessing patient's information. Patient carer actor has an influence on the overall system. Even though it is an external actor, it has the access to the patient records and logs files.

\section{Medicare}

The Medicare actor's roles are to processing the bill from GP, Hospital, Ambulance and the insurance of the Patients. With the use of Smart Homecare, patients cab pays their bills directly. The two options are provided GPs who do bulk billing where Patients just swipe their Medicare card and the fund will have transferred from the Medicare to the respective GP. Whereas, for the GPs who do not provide a bulk billing, the patient can make a payment through Smart Homecare where patient will swipe their credit card and then Medicare card and swiping the credit card to get the money back from Medicare.

\subsection{Conceptual Model for Smart Homecare}

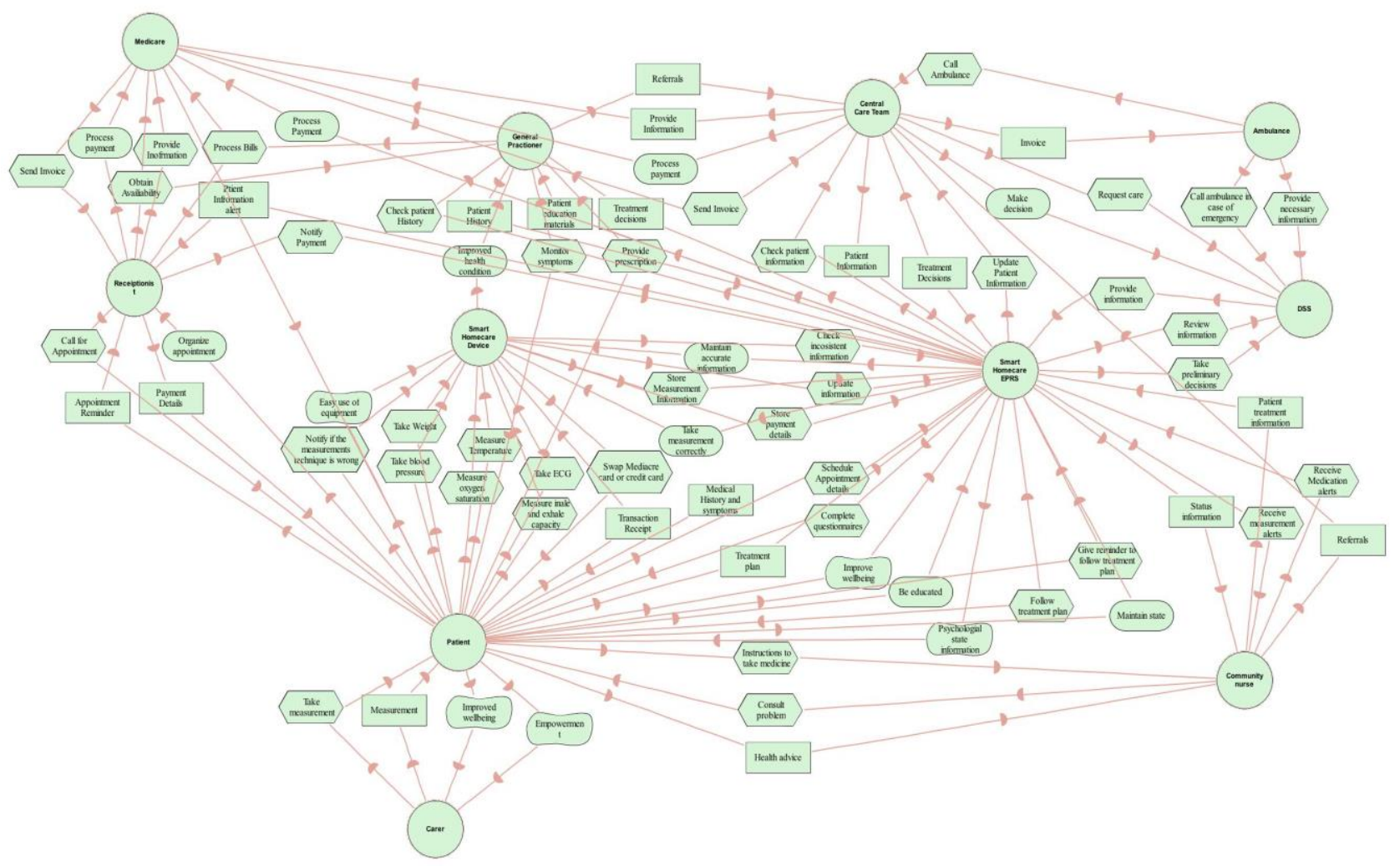

Fig. 8. Proposed conceptual model for smart homecare.

After the identification of actors and roles, a conceptual framework for Smart Homecare using $i^{*}$ organizational model has been developed that expects to have a significant part in minimizing the need of medical assistance for elderly people to be more active for their personal health management in their homes. A proposed Conceptual Smart Homecare is illustrated below in Fig. 8.

In any business process initiative, capturing and understanding the business process is a crucial step. The 
chances are to have ineffective or irrelevant business process while discovering the business process due to the lack of methodology, lack of efficient tools and resources. The two important issues were considered while going through the process discovery and design phase. Firstly, the process is made effective in terms of quality and Secondly the process is optimized in terms of cost efficiency.

Furthermore, improvements in overall communication can develop successful business processes in the health sector. The effective collaboration of process, redundancy is minimized that helps in cost-effective workflows that help in reducing the cost. According to [17] the general objective of these concepts is to enhance enterprise performance to a major higher level while understanding the advantages in relation to cost and time reductions, quality improvements and fast and adaptable response times to patient requirements.

In the medical health sector, there is a specific approach for health management. However, the identified actors such as Receptionist, GP, Smart Homecare device, DSS, Ambulance, Carer, Smart Homecare EPRS helps in reducing the impact of vulnerability and criticality [9]. This approach let all the actors communicated to each other as there is co-related process and goals the actors has. From the Smart Homecare Device, it lets you manage the regular health status and make the appointment, payment through it. The use of technology such as DSS (Decision Support System) and Smart Homecare Enterprises helps in calculating the data and gives you the patients report whereas the Smart Homecare Enterprises is responsible for maintaining the records [17]. Two payment options are available to the patients either through credit card or Medicare card. It eventually helps in reshaping the experience of the patients eliminating the current existing weakness and achieving their goal [18].

\subsection{Proposed Template to Develop Organization Model for Smart Homecare}

We propose the usage of the following template to develop a detailed organisational model for Smart Homecare. We have elaborated the template with sample information.

Table 1. Template to Elicit Information for Organizational Model Development

\begin{tabular}{|c|c|}
\hline \multicolumn{2}{|c|}{ Process Elaboration Template } \\
\hline $\begin{array}{c}\text { Department Name } \\
\text { (Use the department name } \\
\text { if necessary) }\end{array}$ & N/A, External Actor \\
\hline Process ID & E120 Elaboration \\
\hline $\begin{array}{c}\text { Process Name } \\
\text { (Use separate sheet for } \\
\text { each process) }\end{array}$ & Patient Appointment \\
\hline Process Type & Arrange Appointment for Patient \\
\hline $\begin{array}{c}\text { Process Goals and } \\
\text { Rationales } \\
\text { (Use separate sheet for } \\
\text { each process) }\end{array}$ & Provide Medical Support \\
\hline \multicolumn{2}{|c|}{ Activity/ Subprocess Details for the Process } \\
\hline $\begin{array}{c}\text { Activity/ Subprocess } \\
\text { Name and }\end{array}$ & Obtain Availability \\
\end{tabular}




\begin{tabular}{|c|c|c|c|c|}
\hline \multicolumn{2}{|c|}{$\begin{array}{c}\text { Description } \\
\text { (Use separate sheet } \\
\text { for each activity under } \\
\text { the process) }\end{array}$} & & \multicolumn{2}{|c|}{$\begin{array}{c}\text { Organize Appointment } \\
\text { Appointment Reminder } \\
\text { Patient Appointment Alert }\end{array}$} \\
\hline \multicolumn{2}{|c|}{$\begin{array}{l}\text { Responsible Actor(s) } \\
\text { involved in the } \\
\text { activity/subprocess } \\
\quad \text { (Unique list of } \\
\quad \text { Actors(s)) }\end{array}$} & & \multicolumn{2}{|c|}{$\begin{array}{l}\text { - GP } \\
\text { - } \quad \text { Receptionist } \\
\text { - Smart Homecare EPRS } \\
\text { - Patient }\end{array}$} \\
\hline \multicolumn{5}{|c|}{$\begin{array}{l}\text { Relationship / dependencies between responsible actor(s) to achieve / satisfy the above } \\
\text { activity } \\
\text { (Relationship is described as the dependency from source actor on to target actor, use separate } \\
\text { row for each relationship and dependency. This part of the template represents the sequence } \\
\text { and control flow in BPMN(Business Process Models and Notation). }\end{array}$} \\
\hline Source Actor & \multicolumn{2}{|c|}{$\begin{array}{c}\text { Relationship / } \\
\text { Dependency }\end{array}$} & Target Actor & $\begin{array}{l}\text { Additional information / } \\
\text { elaboration on the relationship }\end{array}$ \\
\hline Receptionist & \multicolumn{2}{|c|}{$\begin{array}{c}\text { Obtain } \\
\text { Availability }\end{array}$} & $\overline{\mathrm{GP}}$ & $\begin{array}{l}\text { Receptionist obtains availability from } \\
\text { GP. }\end{array}$ \\
\hline Receptionist & \multicolumn{2}{|c|}{$\begin{array}{c}\text { Call For } \\
\text { Appointment }\end{array}$} & Patient & $\begin{array}{l}\text { Patient calls receptionist for } \\
\text { appointment. }\end{array}$ \\
\hline Patient & \multicolumn{2}{|c|}{$\begin{array}{c}\text { Organize } \\
\text { Appointment }\end{array}$} & Receptionist & $\begin{array}{c}\text { Receptionist organizes appointment } \\
\text { for patient. }\end{array}$ \\
\hline Patient & \multicolumn{2}{|c|}{$\begin{array}{l}\text { Appointment } \\
\text { Reminder }\end{array}$} & Receptionist & $\begin{array}{l}\text { Patient is reminded for appointment } \\
\text { by receptionist. }\end{array}$ \\
\hline $\begin{array}{c}\text { Smart } \\
\text { Homecare } \\
\text { EPRS }\end{array}$ & \multicolumn{2}{|c|}{$\begin{array}{c}\text { Patient } \\
\text { Appointment } \\
\text { Alert }\end{array}$} & Receptionist & $\begin{array}{c}\text { Receptionist alerts Smart Homecare } \\
\text { Telecare EPRS for patient's upcoming } \\
\text { appointments. }\end{array}$ \\
\hline Patient & \multicolumn{2}{|c|}{$\begin{array}{l}\text { Appointment } \\
\text { Alerts }\end{array}$} & $\begin{array}{l}\text { Smart Homecare } \\
\text { EPRS }\end{array}$ & $\begin{array}{l}\text { Smart Homecare EPRS sends alerts to } \\
\text { patient for upcoming appointment. }\end{array}$ \\
\hline \multicolumn{4}{|c|}{ Modeller Signature } & Stakeholder Signature \\
\hline
\end{tabular}

\subsection{Discussion}

In recent times, smart technologies have become so popular that has completely changed the lifestyle we used to have before. The ultimate motto of every technological device in the health domain is to give an easy and safe environment to maintain the health of every people. In addition, Smart Homecare has been the focus where it highlights how the overall process involved in the Health Management System can be incorporated together to make an effective single breed process. The main functionality of this system is to help older people whether suffering from normal diseases or chronic diseases, to remain at home and being able to check their health status and can be updated about their health status. Regardless of any age, disease, people can benefit from this innovation. The benefit of Smart Homecare is to provide multi-functional features combined and support of Decision Support System, Smart Homecare EPRS (Electronic Patient Record System) for Calculating the data provided by the patient and providing the result whereas all the history of the patient would be stored or recorded in Smart Homecare EPRS. This would be 
more applicable for the elder citizens or the patient suffering from the chronic diseases staying at home in a comfortable environment. Moreover, the tremendous advantages it gives like less check- up cost as it saves the time and money for every individual while visiting GP every now and then. Better health living standard is one of the keys to having a healthy life and avoiding the chronic disease with the constant update of your health status as this doesn't bound patient with the check-up limitation. While it not only saves the time but also make the patient more aware of their health status. The post benefits with the implementation of this system are Sustainable and healthy living standard, economically feasible and efficient, Time saving, fewer health complications, multipurpose remote device and the pleasant life standard of the people.

With the concept of Converging multi processes into an efficient single process, it accommodates all the actors that play an essential role in the overall health management such as Hospitals, GP, Ambulance, Carer, Decision Support System, Smart Homecare EPRS. The communication is very crucial as they are interrelated to each other either through task dependency or goal dependency [18]-[22]. The normal phenomena of health check-up is simplified into an extended and very effective way from where the patient can not only get an update about his/her health status but also from making an appointment or even paying a money can be performed through the device. A history of the patient would be stored in Smart Homecare EPRS that would let GP and even Hospital aware about the patient condition and in the case of the emergency ambulance will be available for assistance to serve the patient through [19].

The benefits are not only getting by everyone but also the Government Bodies who has a responsibility of looking after the health of their citizen. However, considering the health system of Australia, when people feel sick they need to visit a GP (General Practitioner). Looking at the situation the GP refer to the specialist or a public hospital for any kind of testing or diagnosis [20]. Citizens are provided with Medicare facility that helps them to go for treatment for free. As the statistics [20] shows the no number of aging people are increasing and expected to increase in near future. As a result, Government is coming up with the new policies that have been deducting the facilities they provide through Medicare. Considerably, focusing on the senior citizen of Australia, it would be very advantageous from both economically and environmentally to offer the service to the people without compromising on the quality of services they have been providing. It is more significant in providing better service while reducing the cost of primary health.

The proposed model leads to the improvements in efficiency and effectiveness of the identified process. With the identification of the requirements of business with changing environments not only helps in improving the efficiency but also increase the productivity of the identified actors like Patients, GP, Carer, Smart Homecare device and so on. It helps in increasing the satisfaction of the patients from the perspective of the service they get in a daily life.

The benefit of Smart Homecare is to provide combined multi-functional features, supported by a DSS, and Smart Homecare EPRS (Electronic Patient Record System). DSS facilitates calculation of data provided by the patient and analyses the result while Smart Homecare EPRS stores all patient records and data. There are significant advantages from the use of this system as check-up cost are lower saving time and money for every individual while visiting GP every now and then. Enjoying better health and, therefore, a higher standard of living, is vital to manage chronic diseases. This conceptual framework proposes that it is possible through constant monitoring of vital signs independent or in addition to GP services. Additional benefits arise from the fact that individuals develop higher awareness of their own health condition. Long term benefit includes a more sustainable and healthy living standard based on a cost and time efficient system.

\section{Conclusion}

Current health solutions are fragmented and mostly does not consider the wider context of in terms of 
problem domain in larger organization setting. We propose a conceptual smart homecare design in primary health care domain using $i^{*}$ organizational modeling notation. For the framework, actors and roles associated with it were identified. The result is a comprehensive conceptual framework that incorporates existing health care elements into a system that focuses on health care management rather than just treatment. This has been achieved by using business processes as the basis for individual elements which have then been combined into a single 'best practice' approach. Our next step is to evaluate the framework using various parameters in terms of consistency, criticality, and vulnerability with the aim of increasing effectiveness and efficiency of the proposed framework.

\section{References}

[1] Perimal-Lewis, L., Vries, D. D., \& Thompsan, C. H. (2014). Discovering the process model using process mining by constructing start-to-end patient journeys. Proceedings of the 7th Australasian Workshop on Health Informatics and Knowledge Management.

[2] Best, J. B. (2015). The politician: A public health problem? The Medical Journal of Australia, 202(8), 452-453.

[3] Billis, A. S., Papageorgiou, E. I., Frantzidis, C. A., Tsatali, M. S., Tsolaki, A. C., \& Bamidis, P. D. (2015). A decision-support framework for promoting independent living and ageing well. IEEE Journal of Biomedical and Health Informatics, 19(1), 199-209.

[4] Dawadi, P., Cook, D., \& Schmitter-Edgecombe, M. (2016). Automated cognitive health assessment from smart home-based behavior data. IEEE Journal of Biomedical and Health Informatics, 20(4), 1188-1194. Retrieved from http://dx.doi.org/10.1109/jbhi.2015.2445754

[5] Metola, E., Bernardos, A. M., \& Casar, J. R. (2013). A multi-device framework to increase self-awareness for health and disease prevention. Proceedings of 2013 IEEE 15th International Conference on e-Health Networking, Applications and Services (Healthcom 2013).

[6] Perimal-Lewis, L., Vries, D. D., \& Thompsan, C. H. (2014). Discovering the process model using process mining by constructing start-to-end patient journeys. Proceedings of the 7th Australasian Workshop on Health Informatics and Knowledge Management.

[7] Best, J. B. (2015). The politician: A public health problem? The Medical Journal of Australia, 202(8), 452-453.

[8] Metola, E., Bernardos, A. M., \& Casar, J. R. (2013). A multi-device framework to increase self-awareness for health and disease prevention. Proceedings of 2013 IEEE 15th International Conference on e-Health Networking, Applications and Services (Healthcom 2013).

[9] Muiingi, M., \& Mbohwa, C. (2013). A fuzzy particle swarm optimization approach for task assignment in home health care. Proceedings of 2013 IEEE International Conference on Industrial Engineering and Engineering Management.

[10] Bhuiyan, M. (2012). Managing Process Design in a Dynamic Organisational Context. Ph.D thesis. Retrieved from http://ro.uow.edu.au/cgi/viewcontent.cgi?article=5557\&context=theses

[11] Gill, T. K., Price, K., Dal Grande, E., Daly, A., \& Taylor, A. W. (2016). Feeling angry about current health status: Using a population survey to determine the association with demographic, health and social factors. BMC Public Health, 16(1).

[12] Cramp, D., \& Carson, E. (2014). A model-based framework for public health: A vehicle for maximising the value of telecare? Proceedings 2000 IEEE EMBS International Conference on Information Technology Applications in Biomedicine. ITAB-ITIS 2000. Joint Meeting Third IEEE EMBS International Conference on Information Technology Applications in Biomedicine (ITAB'00).

[13] Ministry of health. (2012). NSW Pain Management Report. Retrieved from 
http://www.health.nsw.gov.au/,http://www.health.nsw.gov.au/PainManagement/Publications/NSWPain-Management-Report.pdf

[14] Basilakis, J., Lovell, N., \& Celler, B. (2007). A decision support architecture for telecare patient management of chronic and complex disease. Proceedings of 2007 29th Annual International Conference of the IEEE Engineering in Medicine and Biology Society.

[15] Humphreys, J. S., \& Weinand, H. C. (2010). Health status and health care in rural Australia: A case study. Community Health Studies, 13(3), 258-275.

[16] Karim Saeed, O., Said Deeb, O. M. N., Mohammad Ali, O. L., Mustafa, M. S., \& Feng, Z. (2014). Effect of health care quality on nurses by using electronic patients records (EPRs) in Jordanian private hospital. IOSR Journal of Humanities and Social Science, 19(10), 39-45.

[17] Chatterjee, C., \& Srinivasan, V. (2013). Ethical issues in health care sector in India. IIMB Management Review, 25(1), 5.

[18] Liu, W. (2014). Clinical knowledge management: Using extensible markup language to characterize clinical decision support. American Journal of Health-System Pharmacy, 71(12), 994-997.

[19] McCall, C. (2016). Concerns raised over future of medicare in Australia. The Lancet, 388(10042), 323.

[20] Ray, P. P. (2014). Home health hub internet of things (H3 Iot): An architectural framework for monitoring health of elderly people. Proceedings of International Conference on Science, Engineering and Management Research.

[21] George, K., Aleksandar, V., Moshiur, B., Aneesh, K., \& Aditya, G. Combined Approach for Supporting the Business Process Model Lifecycle.

[22] Anna, M. F., Farzana, H., Luba, S., Moshiur, B., Aneesh, K., \& Chandana, W. Enhancing Public Service Delivery through Organisational Modeling.

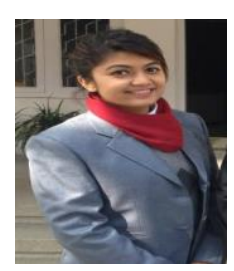

Sujata Basnet is a postgraduate student of information technology majoring in software design and development and business analysis of Charles Sturt University. She has a keen interest on problem solving and innovating the new things that can helps in improving the existing business and process. Her research area includes conceptual modelling, risk management, project management and software requirement engineering.

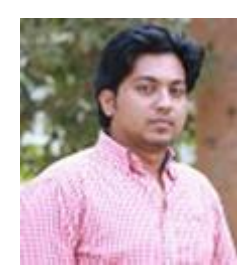

Ashab Abid is an engineering consultant working for a large multinational organization. He has significant working experience in telecommunication industry. He is a graduate in electrical and electronics engineering majoring in computer system architecture and renewable energy technology. He has sharp analytical mind, with a powerful learning towards complex problem solving and always willing to innovate new things which can improve the existing business and technical processes. His research areas include data mining, risk management, renewable energy technology, computer system architecture.

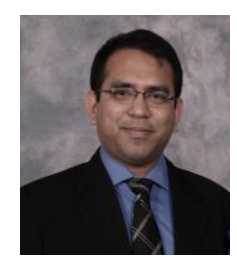

Moshiur Bhuiyan is an experienced IT management consultant, who possesses extensive expertise in management consulting, business analysis, BPM, change management and enterprise architecture. He has significant passion in research and teaching. His research areas include but are not limited to business process discovery \& modelling, process rules and policy integration, process execution, process reengineering and optimization, process lifecycle management, change management, software requirement engineering, cloud computing, ICT governance \& architecture. He has published his works in reputed international conferences and journals. He has served as program committee member and reviewer in several conferences and workshops. He is 
also the founder member of a technology entrepreneurship company named enterprise cloud systems (www.ecloudsys.com) which develops innovative cloud applications.

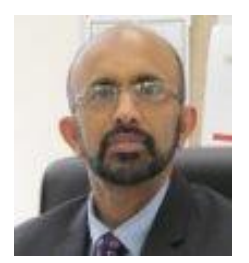

P. W. C. Prasad is an adjunct associate professor with the School of Computing and Mathematics at Charles Sturt University, Australia. Prior to this, he was a lecturer at the United Arab Emirates University in UAE, Multimedia University in Malaysia and also the Informatics Institute of Technology (IIT), Sri Lanka. He gained his undergraduate and postgraduate degrees from St Petersburg State Electrotechnical University in the early 90s and completed his Ph.D studies at the Multimedia University in Malaysia. He is an active researcher in the areas of computer architecture, digital systems, modelling and simulation. He has published more than 100 research articles in computing and engineering journals and conferences proceedings. He has co-authored two books entitled 'digital systems fundamentals' and 'computer systems organization and architecture' published by Prentice Hall. He is a senior member of the IEEE computer society. 